\title{
Modeling the Implementation Context of a Telemedicine Service: Work Domain Analysis in a Surgical Setting
}

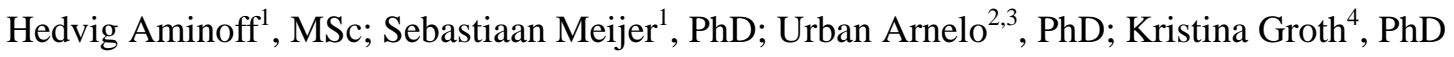 \\ ${ }^{1}$ Biomedical Engineering and Health Systems, KTH Royal Institute of Technology, Stockholm, Sweden \\ ${ }^{2}$ Department of Surgical and Perioperative Sciences, Surgery, Umeå University, Umeå, Sweden \\ ${ }^{3}$ Division of Surgery, Department of Clinical Science, Intervention and Technology, Karolinska Institutet, Stockholm, Sweden \\ ${ }^{4}$ Innovation Center, Karolinska University Hospital, Stockholm, Sweden
}

\section{Corresponding Author:}

Hedvig Aminoff, MSc

Biomedical Engineering and Health Systems

KTH Royal Institute of Technology

Teknikringen 42

Stockholm, 11428

Sweden

Phone: 46734606075

Email: hedvigam@kth.se

\begin{abstract}
Background: A telemedicine service enabling remote surgical consultation had shown promising results. When the service was to be scaled up, it was unclear how contextual variations among different clinical sites could affect the clinical outcomes and implementation of the service. It is generally recognized that contextual factors and work system complexities affect the implementation and outcomes of telemedicine. However, it is methodologically challenging to account for context in complex health care settings. We conducted a work domain analysis (WDA), an engineering method for modeling and analyzing complex work environments, to investigate and represent contextual influences when a telemedicine service was to be scaled up to multiple hospitals.
\end{abstract}

Objective: We wanted to systematically characterize the implementation contexts at the clinics participating in the scale-up process. Conducting a WDA would allow us to identify, in a systematic manner, the functional constraints that shape clinical work at the implementation sites and set the sites apart. The findings could then be valuable for informed implementation and assessment of the telemedicine service.

Methods: We conducted observations and semistructured interviews with a variety of stakeholders. Thematic analysis was guided by concepts derived from the WDA framework. We identified objects, functions, priorities, and values that shape clinical procedures. An iterative "discovery and modeling" approach allowed us to first focus on one clinic and then readjust the scope as our understanding of the work systems deepened.

Results: We characterized three sets of constraints (ie, facets) in the domain: the treatment facet, administrative facet (providing resources for procedures), and development facet (training, quality improvement, and research). The constraints included medical equipment affecting treatment options; administrative processes affecting access to staff and facilities; values and priorities affecting assessments during endoscopic retrograde cholangiopancreatography; and resources for conducting the procedure.

Conclusions: The surgical work system is embedded in multiple sets of constraints that can be modeled as facets of the system. We found variations between the implementation sites that might interact negatively with the telemedicine service. However, there may be enough motivation and resources to overcome these initial disruptions given that values and priorities are shared across the sites. Contrasting the development facets at different sites highlighted the differences in resources for training and research. In some cases, this could indicate a risk that organizational demands for efficiency and effectiveness might be prioritized over the long-term outcomes provided by the telemedicine service, or a reduced willingness or ability to accept a service that is not yet fully developed or adapted. WDA proved effective in representing and analyzing these complex clinical contexts in the face of technological change. The models serve as examples of how to analyze and represent a complex sociotechnical context during telemedicine design, implementation, and assessment. 
(JMIR Form Res 2021;5(6):e26505) doi: 10.2196/26505

\section{KEYWORDS}

telemedicine; telementoring; implementation context; surgical guidance; health technology; usability; work domain analysis; cognitive work analysis

\section{Introduction}

This paper focuses on a successfully trialed telemedicine service for remote surgical guidance [1] that was to be scaled up to four additional hospitals and clinically evaluated. However, there were many technical, social, and organizational differences between the participating clinics, and indications that the acceptance of teleguidance varied [2]. We wanted to account for the implementation context by conducting a work domain analysis (WDA) to systematically investigate what set the sites apart and identify the factors that might come to affect the implementation and clinical outcomes of the telemedicine service [3-5].

\section{Background}

Health technology innovations that appear successful in one setting can produce different outcomes in another context. This may contribute to variability in clinical outcomes and cause failure to scale. There is growing recognition that the complexity of health care presents challenges for evaluating new health information technology (IT) [6] and that high-quality design and evaluation requires considering the context in which new technologies will be used. This paper focuses on systematically charting the implementation context for a telemedicine service for surgical consultation.

The telemedicine service was a practitioner-to-practitioner videoconferencing system designed to enable remote surgical guidance in endoscopic retrograde cholangiopancreatography (ERCP), a technically advanced procedure for biliary and pancreatic disease. The telemedicine innovation, called teleguidance, was successfully trialed through collaboration between a high-volume clinic at a university hospital and a low-volume regional clinic, and health economic modeling demonstrated positive quality impacts [7]. Teleguidance was subsequently scaled up to four additional hospitals and clinically evaluated.

However, there were many technical, social, and organizational differences between the clinics participating in the scale-up process, along with indications that acceptance toward telemedicine services varied among practitioners [2]. This raised concerns about how to successfully implement the service and understand the outcomes. It was unknown if and how contextual variations might affect clinical outcomes or whether telemedicine might interact with daily ERCP work in ways that might affect the implementation and use of teleguidance over time.

Therefore, we wanted to identify important contextual issues to be considered when evaluating the implementation and clinical outcomes by first focusing on factors that shape regular ERCP "work as done" [8] at the teleguidance implementation sites. This required a method that could accommodate the complexity of the clinical work systems $[9,10]$. Methodological concerns about the implementation context, complexity, and the scope of the analysis are discussed in detail in a related paper [11].

\section{Cognitive Systems Engineering}

Cognitive systems engineering $[3,12,13]$ is a systems design discipline for complex settings; it emphasizes that the design and evaluation of technologies must be based on knowledge about the real-world context of their use [14]. Cognitive work analysis (CWA) [3,4] is a set of methods driven by systems theory, where work systems are viewed as fields of practice in which the agents, artifacts, and external world interact to produce outcomes [15]. This set of methods has been used for design and evaluation in a range of sociotechnical systems, including health care [16].

\section{WDA Method}

The first level of analysis in CWA is WDA. WDA is typically performed to provide representations of a complex work setting in the face of technological change (eg, during the design requirements and specification phase, or acquisition evaluation) [5]. This method has proved valuable in the design and evaluation of health technology [17], in the definition of health care team requirements [18,19], and in patient safety work [20].

WDA explicitly focuses on contextual factors by modeling the terms and conditions that shape work in functional terms. WDA provides compact representations that can support systematic investigations of how new technology impacts the overall domain purposes [21] in settings with large variability in behaviors and events as well as during system change [22].

\section{Objectives}

Our aim was to identify intrinsic constraints that shape ERCP work from a clinician's perspective, ranging from physical objects to processes and priorities that affect regular work. A broad WDA would provide a systematic description of the factors shaping regular ERCP work at one hospital, including the macroscopic, mesoscopic, and microscopic levels of the system [23], which are commonly analyzed and represented separately [24]. The graphical format would be useful to contrast the work systems where teleguidance is to be implemented and proactively identify how the telemedicine service might interact with work at the different sites.

The Methods section describes how we modeled daily ERCP work as a work system involving physical components, processes, and goals and intentions, and how this allowed us to contrast the implementation contexts at the hospitals involved and reflect upon how teleguidance might interact with the work systems. 


\section{Methods}

\section{Data Collection}

An ethnographical approach was used, with extensive field work conducted to collect data and generate a deep understanding of the context in a work system [25]. This included three iterations of data collection using a sequence of techniques, moving from a general "rough" level of description to a finer understanding, as Figure 1 shows.

Figure 1. Phases in data collection, analysis, and modeling.

$\left.\begin{array}{r}\text { Field studies and } \\ \text { explorative } \\ \text { interviews: } \\ \text { understanding } \\ \text { ERCP } \\ \text { ERCP is performed } \\ \text { at different } \\ \text { hospitals } \\ \text { Deepening and } \\ \text { representing initial } \\ \text { understanding }\end{array}\right\} \begin{aligned} & -15 \text { trial observations and } 10 \text { informal interviews with } \\ & \text { ERCP practitioners at the central site } \\ & \text { Identifying and reading relevant documents, such as } \\ & \text { organization charts, strategic documents etc. }\end{aligned}$

The focus during the first round of observations and interviews was on the practical aspects of ERCP work, namely identifying everyday work practices, including tradeoffs and challenges encountered by the staff. The aim was to understand the ERCP procedure itself, roles of different stakeholders, and details about the clinical work from the perspective of the ERCP staff. We also read the clinical decision support and strategic documents and spoke to practitioners with administrative and management roles to gain an understanding of the organizational issues shaping the clinical work.

After these steps, a service blueprint [26] was developed as an intermediate, shared representation to externalize our understanding of the different phases of regular work practices and tasks during each phase (see Multimedia Appendix 1, which is in Swedish). The service blueprints were used as a resource to support discussions with practitioners and help compare work practices at the different hospitals.

The second phase of data collection included designing a protocol for semistructured interviews focusing on the details of regular ERCP practices (see Multimedia Appendix 2) and conducting a series of interviews with physicians, nurses, and technical and administrative staff at each of the four remote participant sites. Observations of the work practices, such as how surgery was prepared and conducted at each site, were documented as field notes, and the surgical facilities at the remote sites were documented as images to obtain details regarding the layout and medical equipment available in the operating theaters.

\section{Analysis}

All interviews were recorded and transcribed. The coding work was mainly performed by the first author, with support from the second author. We conducted thematic analyses [27] to identify the constraints mentioned in the interviews; the initial codes were generated by grouping and naming interesting or repeated findings, such as the patterns of activities or the mention of challenges in the work environment or during ERCP. We used the prompts derived from the WDA framework to link our findings to a priori identified themes in line with the abstraction levels suggested by Naikar [5]( see Multimedia Appendix 3).

\section{Modeling}

One of the common WDA representations is the abstraction hierarchy (AH). The AH matrix is a way of modeling the work domain, and it shows means-ends relationships among constraints (eg, how a physical object serves or interferes with system objectives).

The AH can be used as a tool to trace how introducing new technologies and work processes can interact with numerous aspects of work [28]. The AH was constructed using Naikar's method [5] as the main resource, together with feedback from three domain experts, two ERCP surgeons and one project manager.

The modeling focused on the ERCP team subsystem, and these cells were populated at the highest level of detail in the $\mathrm{AH}$ matrices. 
Suggestions regarding system decomposition and populating the cells of the $\mathrm{AH}$ were developed through multiple iterations, and the details are available elsewhere [11].

We worked through several versions of the work system decomposition, identifying systems and subsystems within the hospital organization. We found that the open nature of the hospital systems and constant reorganization made it difficult to define a detailed hierarchical decomposition that would contribute to the analysis. Moreover, after three modeling iterations, we found a satisfactory way to represent the domain as three functional facets: treatment, development, and administration.
These facets are sets of constraints distinguished by the nature of the tasks, competencies, and roles. Individuals can have multiple roles and be involved with several facets, as is the case with senior physicians and nurses who may perform clinical, managerial, research, or teaching/mentoring functions.

\section{Exploring Interactions Among Constraints}

Considering the individual nodes in the $\mathrm{AH}$ and tracing the means-ends links to the levels above and below (Figure 2), the models were used as a tool to verify our understanding of how ERCP is currently performed and further explore possible interactions and system changes when teleguidance is introduced.

Figure 2. How the means-ends structure of an abstraction hierarchy can support the investigation of interactions in a work system.

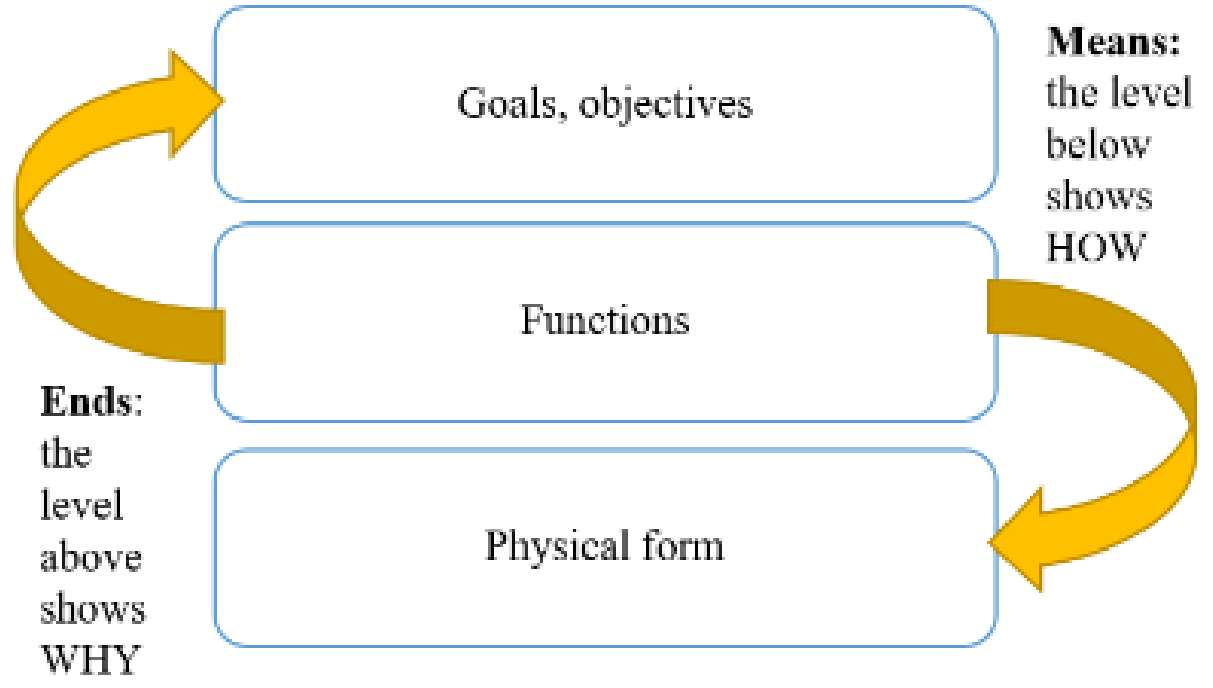

The purpose of these exercises was to elicit new insights about the implementation of teleguidance and determine whether the models provided a representation that different stakeholders could relate to.

\section{Results}

\section{Multiple Models}

Owing to the open nature of the work systems, the scope of our analysis was very wide and deep; we identified many causal (physical) and intentional constraints (goals, priorities, etc). Some constraints were conflicting, such as policies that might cause tradeoffs between clinical performance and economic efficiency.

The complexity of the context was difficult to incorporate within a single $\mathrm{AH}$, and we resolved this by modeling three sets of constraints affecting ERCP procedures, namely the clinical, administrative, and development facets of the domain, as Figure 3 shows. 
Figure 3. Three sets of constraints shaping daily endoscopic retrograde cholangiopancreatography work.

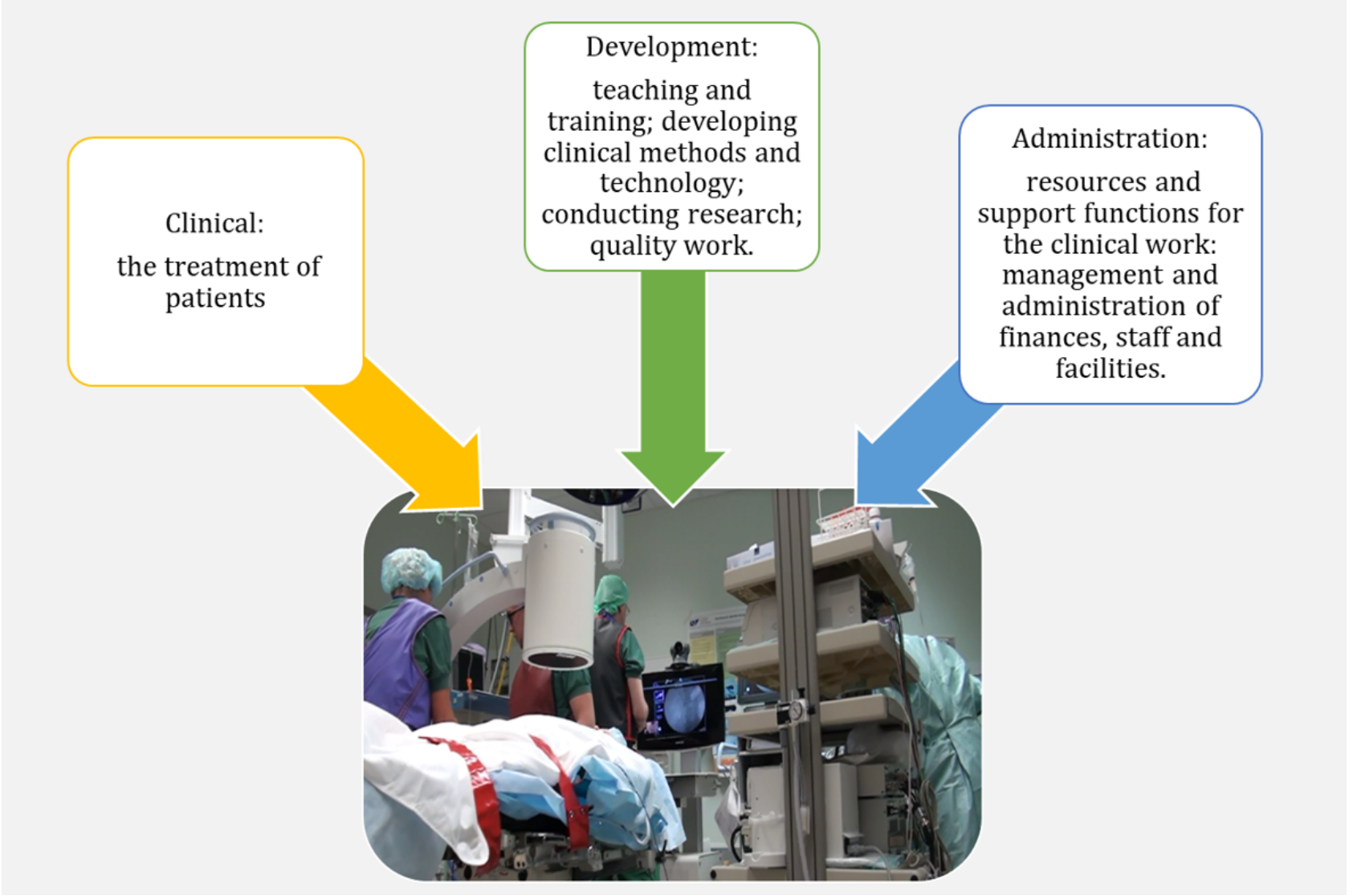

In the following sections, we present the AHs, which were aggregated to increase legibility, and representative examples of constraints; we describe how these can vary between the implementation sites and how the constraints may interact with teleguidance. The clinical facet is described in greater detail than the development and administration facets.

\section{The Clinical Facet}

The clinical facet (Figure 4) represents the constraints that shape the ERCP team's work in terms of the functional purpose, namely "patient diagnosis, relief, or cure through ERCP." The physical entities are the ERCP team members, patients, medical facilities, and medical equipment.

Figure 4. Abstraction hierarchy, clinical facet.

\section{Clinical facet}

\begin{tabular}{|c|c|c|c|c|}
\hline \multicolumn{2}{|l|}{$\begin{array}{l}\text { Functional } \\
\text { purpose }\end{array}$} & \multicolumn{2}{|c|}{$\begin{array}{c}\text { Patient diagnosis, relief, or cure } \\
\text { through ERCP }\end{array}$} & \multirow[b]{2}{*}{ Patient safety } \\
\hline $\begin{array}{c}\text { Values and } \\
\text { priority } \\
\text { measures }\end{array}$ & $\begin{array}{l}\text { Appropriate and } \\
\text { timely treatment }\end{array}$ & $\begin{array}{l}\text { Effectiveness and } \\
\text { efficiency }\end{array}$ & $\begin{array}{l}\text { State-of-the-art } \\
\text { practice }\end{array}$ & \\
\hline $\begin{array}{l}\text { Purpose- } \\
\text { related } \\
\text { functions }\end{array}$ & Situation assessment & Clinical assessment & $\begin{array}{l}\text { Interventional } \\
\text { procedure }\end{array}$ & Team coordination \\
\hline $\begin{array}{c}\text { Object } \\
\text { related } \\
\text { processes }\end{array}$ & $\begin{array}{l}\text { Preparation and } \\
\text { configuration }\end{array}$ & $\begin{array}{l}\text { View, navigate, and } \\
\text { access inner organs }\end{array}$ & $\begin{array}{l}\text { Support and } \\
\text { assistance }\end{array}$ & Communication \\
\hline Objects & Staff & Patients & Facilities and IT & $\begin{array}{l}\text { Medical supplies and } \\
\text { equipment }\end{array}$ \\
\hline
\end{tabular}


The set of possible clinical actions during an ERCP session is largely determined by causal constraints such as the patient's condition, staff competencies, and capabilities and limitations of the available technology and devices. Teleguidance introduced new physical equipment and staff to the ERCP team, providing new affordances and constraints that propagate throughout the clinical facet.

Constraints were represented in considerably higher detail during modeling. Multimedia Appendix 4 shows a cropped image of a detailed model of the clinical facet.

\section{Values and Priority Measures}

The values and priority measures show the criteria that must be respected for the clinical facet to achieve its functional purposes and those guiding decision-making and tradeoffs during procedures (eg, between patient safety and quality on the one hand, and efficiency on the other hand).

We visualized four values and priority measures: appropriate and timely treatment; effectiveness and efficiency; state-of-the-art practice; and patient safety (see Multimedia Appendix 5).

Multimedia Appendix 6 shows an example of how "appropriateness," a value/priority constraint, differs among hospitals, and how this might interact with teleguidance. Textbox 1 shows an example transcript regarding findings linked to the abstracted constraint "appropriateness."

Textbox 1. Sample transcript showing value and priority measures: appropriate treatment.

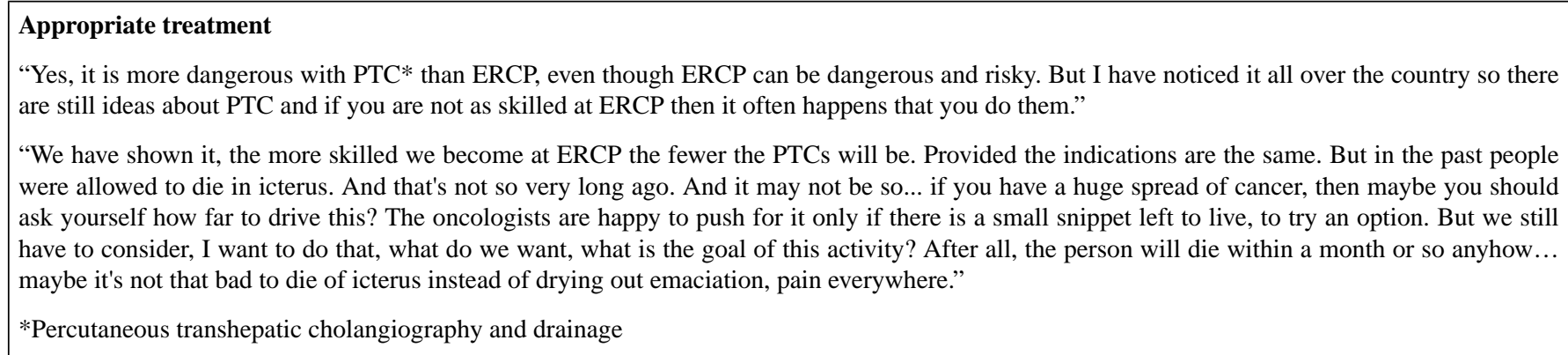

\section{Purpose-Related Functions}

The purpose-related functions represent the general functions that the ERCP work system must fulfill to achieve its functional purpose.

We defined four main functions: situation assessment, clinical assessment, interventional procedure, and team coordination (see Multimedia Appendix 7).

Multimedia Appendix 8 illustrates how this constraint shapes work, how it can vary between sites, and how it might interact with teleguidance.

\section{Object-Related Processes}

The object-related processes level represents the functional capabilities of physical objects, namely the use of physical objects, and their properties and affordances.

We defined four main object-related processes: preparation and configuration; view, navigate, and access inner organs; support and assistance; and communication (see Multimedia Appendix 9).
Multimedia Appendix 10 provides an example of the constraint "preparation and configuration."

\section{Physical Objects}

The physical objects level shows objects that afford functional capabilities to the system. Causal constraints such as patient conditions, staff availability and competencies, and the capabilities and limitations of the technology and devices in an ERCP clinic constrain the set of possible clinical actions during an ERCP session.

We grouped the large number of physical objects required during ERCP procedures into four main categories: staff; patients; facilities and IT; and medical supplies and equipment (Multimedia Appendix 11).

Multimedia Appendix 12 provides an example of the constraint "facilities and IT."

\section{The Administrative Facet}

The administrative facet (Figure 5) was conceptualized as part of the domain that provides the resources for "primary" clinical work. 
Figure 5. Abstraction hierarchy, administrative facet.

Administrative facet

Hospital level

\begin{tabular}{|c|c|c|c|c|c|c|c|c|}
\hline & & \\
\hline $\begin{array}{l}\text { Functional } \\
\text { purpose }\end{array}$ & \multicolumn{3}{|c|}{$\begin{array}{l}\text { Provision of highly specialized health } \\
\text { care according to national mission }\end{array}$} & \multicolumn{5}{|c|}{$\begin{array}{l}\text { Ensure that ERCP is performed safely and } \\
\text { efficiently based on allocated resources }\end{array}$} \\
\hline $\begin{array}{l}\text { Values and } \\
\text { priority } \\
\text { measures }\end{array}$ & $\begin{array}{l}\text { Optimal use of } \\
\text { resources }\end{array}$ & $\begin{array}{l}\text { Health care } \\
\text { equity and } \\
\text { quality }\end{array}$ & \multicolumn{2}{|c|}{ Patient safety } & \multicolumn{2}{|c|}{$\begin{array}{l}\text { Balanced } \\
\text { budget }\end{array}$} & & $\begin{array}{l}\text { ficient } \\
\text { rkflow }\end{array}$ \\
\hline $\begin{array}{l}\text { Purpose- } \\
\text { related } \\
\text { functions }\end{array}$ & $\begin{array}{l}\text { Strategic } \\
\text { decision } \\
\text { making }\end{array}$ & \multicolumn{2}{|c|}{$\begin{array}{l}\text { Allocation of financial } \\
\text { resources and funding }\end{array}$} & \multicolumn{2}{|c|}{$\begin{array}{l}\text { Workflow and } \\
\text { staff } \\
\text { management }\end{array}$} & \multicolumn{3}{|c|}{$\begin{array}{l}\text { Monitoring resources, } \\
\text { finances, and clinical } \\
\text { outcomes }\end{array}$} \\
\hline $\begin{array}{l}\text { Object } \\
\text { related } \\
\text { processes }\end{array}$ & $\begin{array}{l}\text { Technical and } \\
\text { health care } \\
\text { agreements }\end{array}$ & \multicolumn{2}{|c|}{$\begin{array}{c}\text { Management of } \\
\text { facilities and } \\
\text { technology }\end{array}$} & \multicolumn{2}{|c|}{$\begin{array}{c}\text { Financial and } \\
\text { logistical } \\
\text { processes }\end{array}$} & \multicolumn{2}{|c|}{$\begin{array}{l}\text { Facility and } \\
\text { equipment } \\
\text { processes }\end{array}$} & $\begin{array}{l}\text { Clinical } \\
\text { processes }\end{array}$ \\
\hline Objects & Facilities & \multicolumn{2}{|c|}{ Software and databases } & \multicolumn{2}{|c|}{$\begin{array}{l}\text { Staff and } \\
\text { patients }\end{array}$} & \multicolumn{2}{|c|}{$\begin{array}{c}\text { Medical } \\
\text { supplies and } \\
\text { equipment }\end{array}$} & $\begin{array}{l}\text { Standards } \\
\text { and } \\
\text { guidelines }\end{array}$ \\
\hline
\end{tabular}

This facet is largely shaped by intentional constraints such as institutional objectives, organizational and management policies, legislations, and regulations. The administrative facet also places demands on work performance, such as efficiency. Although efficiency demands are considered even during surgery, these demands are largely controlled from outside the clinical facet, which is emphasized in our model.

Individuals can play multiple roles and be involved with several facets, as is the case with senior physicians and nurses who may be directly involved in an ERCP procedure (clinical facet) while also executing managerial, research, and teaching/mentoring functions.

We arrived at two levels of decomposition when we modeled the university hospital, one at the hospital level and the other involving the subsystem "ERCP unit." Although the administrative facet largely set intentional constraints on ERCP work, there were also causal constraints that might affect teleguidance.

All hospitals were under considerable pressure for increasing their efficiency and undergoing constant reorganization. At the hospital level, this was represented as the values and priority measure "optimal use of resources," and at the unit level, it was represented as "balanced budget" and "efficient workflow."

Multimedia Appendix 13 shows an example of how the purpose-related function "strategic decision-making" in the administrative facet might affect teleguidance. More examples are presented in Multimedia Appendix 14.

\section{The Development Facet}

The development facet (Figure 6) is distinguished from the administrative facet owing to its focus on training, research, and quality management, which are the characteristics of advanced clinical practices. In many cases, funding and accountability for these activities are external to the ERCP work system; clinical education and training are often linked to an educational facility; research funding is external; and clinical quality and patient safety criteria are set according to standards and regulations. However, many development activities take place during procedures, such as research activities (eg, documenting unusual physiological features) or teaching and training activities (eg, taking extra time for instruction or allowing a less experienced practitioner operate equipment under supervision). 
Figure 6. Abstraction hierarchy, development facet.

\section{Development facet}

Hospital level

ERCP unit level

\begin{tabular}{|c|c|c|c|c|c|c|}
\hline $\begin{array}{l}\text { Functional } \\
\text { purpose }\end{array}$ & $\begin{array}{l}\text { Provide medical } \\
\text { teaching and } \\
\text { training }\end{array}$ & $\begin{array}{l}\text { Management of research } \\
\text { and development in } \\
\text { medicine and technology }\end{array}$ & \multicolumn{2}{|c|}{$\begin{array}{l}\text { ERCP-related } \\
\text { development and } \\
\text { research }\end{array}$} & \multicolumn{2}{|c|}{$\begin{array}{c}\text { Teaching and training } \\
\text { of medical staff }\end{array}$} \\
\hline $\begin{array}{l}\text { Values and } \\
\text { priority } \\
\text { measures }\end{array}$ & $\begin{array}{l}\text { Improved } \\
\text { outcomes }\end{array}$ & $\begin{array}{l}\text { Academic and } \\
\text { professional status }\end{array}$ & $\begin{array}{l}\text { Best practice, } \\
\text { professional } \\
\text { values }\end{array}$ & \multicolumn{2}{|c|}{$\begin{array}{l}\text { Well-trained } \\
\text { ERCP team }\end{array}$} & $\begin{array}{c}\text { Increased } \\
\text { knowledge } \\
\text { about ERCP }\end{array}$ \\
\hline $\begin{array}{l}\text { Purpose- } \\
\text { related } \\
\text { functions }\end{array}$ & & & $\begin{array}{l}\text { Clinical } \\
\text { training }\end{array}$ & \multicolumn{2}{|c|}{$\begin{array}{l}\text { Studies and } \\
\text { clinical trials }\end{array}$} & $\begin{array}{l}\text { Tracking } \\
\text { outcomes }\end{array}$ \\
\hline $\begin{array}{l}\text { Object } \\
\text { related } \\
\text { processes }\end{array}$ & & & \multicolumn{2}{|c|}{$\begin{array}{c}\text { Teaching/Supervision/ } \\
\text { Mentoring }\end{array}$} & \multicolumn{2}{|c|}{$\begin{array}{l}\text { Study design, data } \\
\text { collection, and data } \\
\text { storage }\end{array}$} \\
\hline Objects & & & $\begin{array}{l}\text { Scientific } \\
\text { publications, } \\
\text { guidelines }\end{array}$ & \multicolumn{2}{|c|}{$\begin{array}{c}\text { Quality } \\
\text { databases and } \\
\text { EHR }\end{array}$} & $\begin{array}{c}\text { Staff, } \\
\text { students and } \\
\text { trainees }\end{array}$ \\
\hline
\end{tabular}

The development facet is accorded higher priority at the university hospital, where part of the functional purpose includes a mission to provide development, education, and training at the national level.

Many aspects of the development facet appeared to motivate the staff we interviewed, and academic and professional statuses were important aspects for being regarded as trustworthy team members. At the regional hospitals, there were expectations that teleguidance would strengthen the development facet by not only increasing opportunities for training but also for participating in research activities.

Multimedia Appendix 15 provides an example of how a constraint in the development facet might affect teleguidance.

\section{Discussion}

\section{Principal Results}

The ERCP work system is an open system as there are factors beyond the control of the clinical team, which influence how ERCP procedures are conducted. The high number of factors that could potentially affect each procedure led us to characterize the ERCP work context as having three facets, representing clinical work as the primary field of interest, and administration and development as complementary fields of the domain, which provide resources for clinical work.

Each facet served as a "dimension" along which we could reason about the differences between the implementation sites and how the different sets of constraints affecting ERCP could impact the implementation of teleguidance.

Although the clinical and administrative facets in some aspects reflected organizational partitions, the development facet was clearly not reflected within the organizational structures. However, development is an important aspect of the work domain, which motivates staff and shapes daily clinical work in the highly specialized and constantly evolving field of ERCP, where quality work, training, research, and design of medical equipment are pervasive.

\section{Specific Findings}

The implementation sites could be described with the same AHs and compared by contrasting how specific constraints were instantiated.

The functional purposes of the clinical facet show the ERCP team's primary objectives, namely "patient diagnosis, relief, or cure through ERCP." Teleguidance will not change the functional purpose, but it will affect the constraints through which this purpose is achieved.

During procedures, we expect teleguidance to mainly support the purpose-related functions of clinical assessment and interventional procedures by advising how to interpret imagery or providing specific suggestions for handling a certain instrument.

Teleguidance may create challenges in the functions of "situation assessment" and "team coordination." Situation assessment will change in some ways during teleguidance sessions because team members will be in different locations, and there are risks that the remote surgeon and on-site team might perceive the situation differently (eg, the guiding surgeon may miss information that is apparent to the on-site team).

Team coordination may be affected in ways we do not yet understand as the guiding surgeon becomes part of a geographically and organizationally distributed clinical team that requires cognitive, practical, and administrative coordination.

Teleguidance may also cause differences in the values and priorities among clinical practitioners to surface during 
teleguidance sessions, as shown by the example of appropriateness.

The broad definition of the ERCP work system allowed us to identify constraints that shape events during procedures, along with the object-related processes included in in the work prior to the clinical procedure, such as preparation and configuration. An example is how handling the telemedicine equipment can affect the workload of the assisting staff; at two of the hospitals, the staff would need to spend additional time for preparation and configuration as they must fetch and set up the teleguidance cart, as well as establish a functioning video link. In an already strained work setting, this inconvenience may very well lead to negative experiences with teleguidance over time.

Regarding the "secondary" facets of the domain, the AHs provide some indications of how technical and administrative issues may play out more significantly over time, such as technical responsibility for service and reimbursement issues. We expect that the initial mismatches between the administrative facets can be overcome if the priorities and responsibilities for development work are clear.

If development activities are not a priority, then there is a risk that users will not have the time and resources necessary to handle the awkwardness of work process adaptations.

\section{Comparison With Prior Work}

There are prior examples of WDA that distinguish primary operations and resource management through multiple models, showing the different stakeholder perspectives or facets of a problem [5]. There are also examples of behavioral studies involving health care work systems, which differentiate clinical work and the infrastructure and resources for this work, conceptualizing health care work in terms of primary (clinical) and secondary (billing, audit, and management) work activities [29].

In our case, a third facet, development, is relevant, and this highlights that teleguidance is an effort to facilitate training and quality assurance in routine clinical ERCP practices and the control and constraints for these aspects appear different from the clinical and administration facets.

\section{Limitations}

There are many ways to construct AHs, and the answer to the question of whether it is well done in this study lies in issues such as the boundary definition and conceptualization of abstraction levels, goals, and objects. These aspects were continually addressed during the numerous iterations for creating the AHs.

Owing to the broad system definition and the open nature of the work system, it was not easy to achieve a hierarchical decomposition, and we initially struggled to represent the wide array of constraints. The facets presented a solution to this dilemma.

WDA is developed for complex settings that are resistant to deterministic analysis because of their nature. Therefore, AHs cannot be objectively correct or complete; the highlight of this study is that the models provide a structured and accountable way to reason flexibly and imaginatively on how constraints from multiple system levels interact.

\section{Conclusions}

According to numerous reviews and policy documents, system dynamics and complexity should be considered during the design and evaluation of technological change in health care [30]. This includes the contextual factors constituting "the normal conditions of practice," thus contributing to the implementation outcomes [31]. Our WDA serves as an example of how a complex clinical implementation context can be analyzed and represented in a in a granular yet structured manner while also showing the interactions among the system elements.

We identified clinical, development, and administrative facets of the work domain. These facets represent the general aspects of clinical work systems as sets of contextual factors that should be factored in during the design and implementation of any telemedicine service.

\section{Future Work}

The AHs can serve as artifacts to support the shared understanding required for multidisciplinary collaboration, which is a prerequisite for successful human-system integration [32] (eg, by increasing project managers' understanding of project complexities). This may be extremely valuable in participatory development processes such as contextual inquiries and value specifications, which are important for developing a holistic implementation approach [33].

The models may also be valuable for providing the necessary insights regarding proactive project risks and patient safety management during implementation [34] as well as for guiding clinical and project evaluations [11].

\section{Conflicts of Interest}

None declared.

\section{Multimedia Appendix 1}

Service blueprint showing the processes involved prior to, during, and after endoscopic retrograde cholangiopancreatography (in Swedish).

[PNG File, 319 KB-Multimedia Appendix 1]

\section{Multimedia Appendix 2}

Protocol for semistructured interviews. ERCP: endoscopic retrograde cholangiopancreatography. 
[PNG File, $61 \mathrm{~KB}-$ Multimedia Appendix 2]

\section{Multimedia Appendix 3}

Coding categories and criteria for qualitative data analysis. ERCP: endoscopic retrograde cholangiopancreatography.

[PNG File, 28 KB-Multimedia Appendix 3]

\section{Multimedia Appendix 4}

Partial view of a detailed model of the clinical facet. This image shows the high level of detail in which we modeled the domain, prior to aggregating the abstraction hierarchies.

[PNG File, 89 KB-Multimedia Appendix 4]

\section{Multimedia Appendix 5}

Values and priority measures.

[PNG File, 39 KB-Multimedia Appendix 5]

\section{Multimedia Appendix 6}

Example of the value/priority constraint "appropriateness" showing how it diverged among hospitals and how this might interact with teleguidance. ERCP: endoscopic retrograde cholangiopancreatography.

[PNG File, 73 KB-Multimedia Appendix 6]

\section{Multimedia Appendix 7}

Purpose-related functions.

[PNG File, 40 KB-Multimedia Appendix 7]

\section{Multimedia Appendix 8}

Example of purpose-related function: team coordination. ERCP: endoscopic retrograde cholangiopancreatography.

[PNG File, 67 KB-Multimedia Appendix 8]

\section{Multimedia Appendix 9}

Object-related processes. ERCP: endoscopic retrograde cholangiopancreatography.

[PNG File, 38 KB-Multimedia Appendix 9]

\section{Multimedia Appendix 10}

Example of object-related processes: preparation and configuration. ERCP: endoscopic retrograde cholangiopancreatography. [PNG File, 57 KB-Multimedia Appendix 10]

\section{Multimedia Appendix 11}

Physical objects (aggregated). ERCP: endoscopic retrograde cholangiopancreatography; IT: information technology.

[PNG File, $30 \mathrm{~KB}$-Multimedia Appendix 11]

\section{Multimedia Appendix 12}

Example of physical objects: facilities and information technology.

[PNG File, 36 KB-Multimedia Appendix 12]

\section{Multimedia Appendix 13}

Example of how the purpose-related function "strategic decision-making" might interact with teleguidance. ERCP: endoscopic retrograde cholangiopancreatography.

[PNG File, 22 KB-Multimedia Appendix 13] 


\section{Multimedia Appendix 14}

Examples of constraints in the administrative facet that might affect teleguidance. ERCP: endoscopic retrograde cholangiopancreatography; IT: information technology.

[PNG File, 62 KB-Multimedia Appendix 14]

\section{Multimedia Appendix 15}

Example of how a constraint in the development facet might affect teleguidance. ERCP: endoscopic retrograde cholangiopancreatography.

[PNG File, 50 KB-Multimedia Appendix 15]

\section{References}

1. Påhlsson HI, Groth K, Permert J, Swahn F, Löhr M, Enochsson L, et al. Telemedicine: an important aid to perform high-quality endoscopic retrograde cholangiopancreatography in low-volume centers. Endoscopy 2013;45(5):357-361. [doi: 10.1055/s-0032-1326269] [Medline: 23468194]

2. Aminoff H, Meijer S, Arnelo U, Frennert S. Telemedicine for remote surgical guidance in endoscopic retrograde cholangiopancreatography: mixed methods study of practitioner attitudes. JMIR Form Res 2021 Jan 11;5(1):e20692 [FREE Full text] [doi: 10.2196/20692] [Medline: $\underline{\text { 33427670] }}$

3. Rasmussen J, Pejtersen A, Goodstein L. Cognitive Systems Engineering. New York, NY: John Wiley \& Sons, Inc; 1994.

4. Vicente K. Cognitive Work Analysis: Toward Safe, Productive, and Healthy Computer-Based Work. Boca Raton, FL: CRC Press; 1999.

5. Naikar N. Work Domain Analysis: Concepts, Guidelines, and Cases. Baton Rouge, LA: CRC Press; 2013.

6. Plsek PE, Greenhalgh T. Complexity science: the challenge of complexity in health care. BMJ 2001 Sep 15;323(7313):625-628 [FREE Full text] [doi: 10.1136/bmj.323.7313.625] [Medline: 11557716]

7. Brinne Roos J, Bergenzaun P, Groth K, Lundell L, Arnelo U. Telepresence-teleguidance to facilitate training and quality assurance in ERCP: a health economic modeling approach. Endosc Int Open 2020 Mar;8(3):E326-E337 [FREE Full text] [doi: 10.1055/a-1068-9153] [Medline: 32118106]

8. Hollnagel E. Why is work-as-imagined different from work-as-done? In: Resilient Health Care. Baton Rouge, LA: CRC Press; 2015:279-294.

9. Shiell A, Hawe P, Gold L. Complex interventions or complex systems? Implications for health economic evaluation. BMJ 2008 Jun 07;336(7656):1281-1283 [FREE Full text] [doi: 10.1136/bmj.39569.510521.AD] [Medline: 18535071]

10. Greenhalgh T, Papoutsi C. Studying complexity in health services research: desperately seeking an overdue paradigm shift. BMC Med 2018 Jun 20;16(1):95 [FREE Full text] [doi: 10.1186/s12916-018-1089-4] [Medline: 29921272]

11. Aminoff H, Meijer S. Accommodating complexity in telemedicine evaluation: using work domain analysis to analyze and represent the implementation context of a telemedicine service. JMIR Preprints. Preprint posted online on December 17,2020. This is a link to a preprint of a commentary article we have submitted [FREE Full text] [doi: 10.2196/preprints.26580]

12. Woods D, Roth E. Cognitive systems engineering. In: Helander M, editor. Handbook of Human-Computer Interaction. Amsterdam, Netherlands: North-Holland; 1988:3-43.

13. Smith P, Hoffman R. Cognitive Systems Engineering: The Future for a Changing World. Boca Raton, FL: CRC Press; 2018.

14. Flach JM, Tanabe F, Monta K, Vicente KJ, Rasmussen J. An ecological approach to interface design. In: Proceedings of the Human Factors and Ergonomics Society Annual Meeting. Los Angeles, CA: SAGE Publications; 2016 Nov 05 Presented at: The Human Factors and Ergonomics Society Annual Meeting; 1998; Chicago, Illinois p. 295-299. [doi: $\underline{10.1177 / 154193129804200324]}$

15. Read GJ, Salmon PM, Lenné MG, Stanton NA. Designing sociotechnical systems with cognitive work analysis: putting theory back into practice. Ergonomics 2015;58(5):822-851. [doi: 10.1080/00140139.2014.980335] [Medline: 25407778]

16. Jiancaro T, Jamieson GA, Mihailidis A. Twenty years of cognitive work analysis in health care. J Cogn Eng Decis Mak 2013 May 29;8(1):3-22. [doi: 10.1177/1555343413488391]

17. Benda PJ, Sanderson PM. Representation of changes to anesthesia work domain and activity structures. Proc Hum Factors Ergon Soc Annu Meet 2016 Nov 06;43(8):563-567. [doi: 10.1177/154193129904300803]

18. Burns C, Torenvliet G, Chalmers B, Scott S. Work domain analysis for establishing collaborative work requirements. Proc Hum Factors Ergon Soc Annu Meet 2009 Oct 19;53(4):314-318. [doi: 10.1518/107118109X12524441080984]

19. Cassin BR, Barach PR. Balancing clinical team perceptions of the workplace: applying 'work domain analysis' to pediatric cardiac care. Prog Pediatr Cardiol 2012 Jan;33(1):25-32. [doi: 10.1016/j.ppedcard.2011.12.005]

20. Pickup L, Lang A, Atkinson S, Sharples S. The dichotomy of the application of a systems approach in UK healthcare the challenges and priorities for implementation. Ergonomics 2018 Jan;61(1):15-25. [doi: 10.1080/00140139.2017.1306632] [Medline: 28306384] 
21. Jenkins DP, Stanton NA, Salmon PM, Walker GH. Using work domain analysis to evaluate the impact of technological change on the performance of complex socio-technical systems. Theor Issues Ergon Sci 2011 Jan;12(1):1-14. [doi: 10.1080/14639220903353401]

22. Vicente KJ. Task analysis, cognitive task analysis, cognitive work analysis: what's the difference? Proc Hum Factors Ergon Soc Annu Meet 2016 Nov 05;39(9):534-537. [doi: 10.1177/154193129503900921]

23. Greenhalgh T, Stones R. Theorising big IT programmes in healthcare: strong structuration theory meets actor-network theory. Soc Sci Med 2010 May;70(9):1285-1294. [doi: 10.1016/j.socscimed.2009.12.034] [Medline: 20185218]

24. Greenhalgh T, Shaw S, Wherton J, Vijayaraghavan S, Morris J, Bhattacharya S, et al. Real-world implementation of video outpatient consultations at macro, meso, and micro levels: mixed-method study. J Med Internet Res 2018 Apr 17;20(4):e150 [FREE Full text] [doi: 10.2196/jmir.9897] [Medline: 29625956]

25. Morgan-Trimmer S, Wood F. Ethnographic methods for process evaluations of complex health behaviour interventions. Trials 2016 May 04;17(1):232 [FREE Full text] [doi: 10.1186/s13063-016-1340-2] [Medline: 27142662]

26. Lynn Shostack G. How to design a service. Eur J Mark 1982 Jan 21;16(1):49-63. [doi: 10.1108/EUM0000000004799] [Medline: 5637250]

27. Braun V, Clarke V. Using thematic analysis in psychology. Qual Res Psychol 2006 Jan;3(2):77-101. [doi: 10.1191/1478088706qp063oa]

28. Jenkins D, Stanton NA, Walker GH. Cognitive Work Analysis: Coping with Complexity. London, UK: CRC Press; Jan 2017.

29. Berg M. The search for synergy: interrelating medical work and patient care information systems. Methods Inf Med 2018 Feb 08;42(4):337-344. [doi: 10.1055/s-0038-1634227]

30. Beenkens FP. Context dependency of medical devices. The Priority Medical Devices Project. Geneva, Switzerland: World Health Organization; 2010. URL: https://apps.who.int/iris/handle/10665/70456 [accessed 2021-06-07]

31. May CR, Johnson M, Finch T. Implementation, context and complexity. Implement Sci 2016 Oct 19;11(1):141 [FREE Full text] [doi: 10.1186/s13012-016-0506-3] [Medline: 27756414]

32. Pew RW, Mavor AS, editors. Human-System Integration in the System Development Process: A New Look. Washington DC, USA: National Academies Press; 2007.

33. van Gemert-Pijnen JEWC, Nijland N, van Limburg M, Ossebaard HC, Kelders SM, Eysenbach G, et al. A holistic framework to improve the uptake and impact of eHealth technologies. J Med Internet Res 2011 Dec 05;13(4):e111 [FREE Full text] [doi: 10.2196/jmir.1672] [Medline: 22155738]

34. Augustsson H, Churruca K, Braithwaite J. Change and improvement 50 years in the making: a scoping review of the use of soft systems methodology in healthcare. BMC Health Serv Res 2020 Nov 23;20(1):1063 [FREE Full text] [doi: 10.1186/s12913-020-05929-5] [Medline: 33228657]

\author{
Abbreviations \\ AH: abstraction hierarchy \\ CWA: cognitive work analysis \\ ERCP: endoscopic retrograde cholangiopancreatography \\ IT: information technology \\ WDA: work domain analysis
}

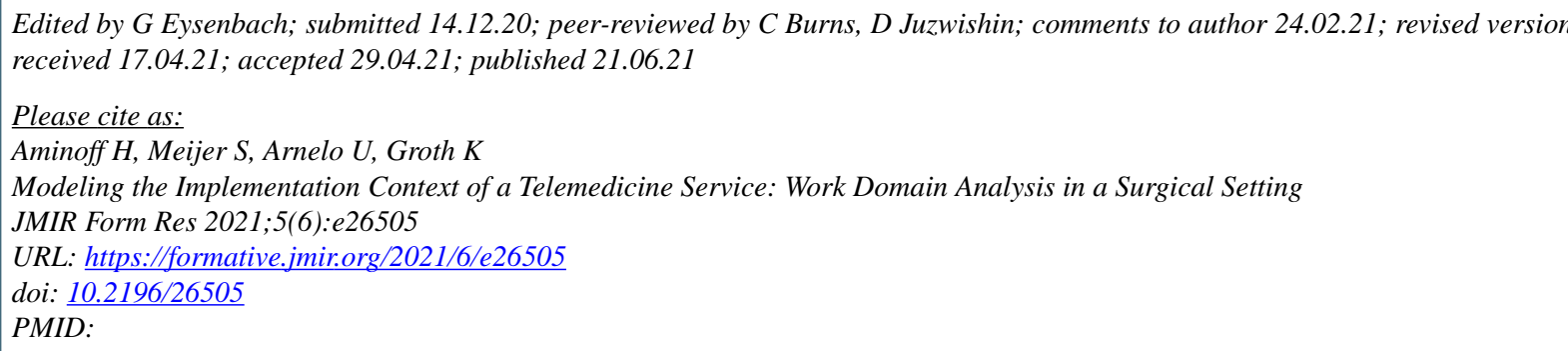

CHedvig Aminoff, Sebastiaan Meijer, Urban Arnelo, Kristina Groth. Originally published in JMIR Formative Research (https://formative.jmir.org), 21.06.2021. This is an open-access article distributed under the terms of the Creative Commons Attribution License (https://creativecommons.org/licenses/by/4.0/), which permits unrestricted use, distribution, and reproduction in any medium, provided the original work, first published in JMIR Formative Research, is properly cited. The complete 
bibliographic information, a link to the original publication on https://formative.jmir.org, as well as this copyright and license information must be included. 